\title{
Addressing The Challenge Of Strategic Alignment Faced By Small And Medium- Sized Entities During The Selection Of Accounting Software Packages
}

William Arthur Bishop, Stellenbosch University, South Africa

\begin{abstract}
Alignment between an entity's strategic business objectives and its information systems (ISs) has recently received research attention. Currently, small and medium-sized entities (SMEs) still face the challenge of successfully aligning their strategic business objectives with their ISs. Various small generic accounting software packages are available for purchase by SMEs. These accounting packages all have functionalities that enable SMEs to keep proper accounting records. However, due to their generic nature, these accounting packages do not always have sufficient functionalities to drive the SMEs' strategic business objectives, resulting in IS misalignment. Not selecting the correct accounting software package will result in the accounting software not addressing the strategic business needs of the SME.
\end{abstract}

The purpose of this study is to review and discuss the challenges faced by SMEs when selecting generic accounting packages and to develop a mapping between strategic business objectives commonly found within SMEs and software package functionalities that SMEs can refer to during the selection and implementation of new accounting software packages. This is accomplished on a non-empirical basis through a review of pertinent literature.

In order for a SME to select the correct accounting software package, it is important that it invest time and effort in considering the software functionalities provided by the software package and map it against its strategic business imperatives to prevent failure of the package.

Keywords: Strategic Alignment; Small And Medium Sized Entities; Business Objectives; Accounting Software Packages

\section{INTRODUCTION AND BACKGROUND}

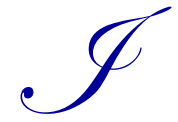

mplementing a new accounting information system (IS) for a business is a costly process that requires considerable time and skills. Hedtke (2007) explains how various small accounting packages have everything that small and medium-sized entities (SMEs) require to operate successfully. These smaller accounting packages are generally more affordable, easy to set-up and user-friendly. SMEs generally prefer to purchase and install generic accounting packages and use them to manage their entire business operations rather than developing their own customised packages due to capacity constraints and costs, as well as the time and information technology (IT) skills that may be required (Blili \& Raymond, 1993). In a survey conducted by Temtime, Chinyoka and Shunda (2003) it was found that word-processing systems are used the most by SMEs, followed by accounting packages and spreadsheets.

Many authors, such as Davenport (1998), have mentioned the importance of aligning accounting package functionalities with the business objectives, specifically on a strategic level. The functionalities of most small accounting packages are mostly limited and generic and require low costs to maintain (Temtime et al., 2003). As a result, it might have all the functionalities for a proper accounting system, but may fail to provide functionalities that 
successfully manage the entire business system and succeed in reaching the strategic goals of SMEs. Davenport (1998) explains how companies fail to align their business and IT needs, resulting in business system failure. Whenever the IS of an entity fails to provide the outputs required by the user or does not function as required, it can be seen as business system failure (Dwivedi et al., 2015). Instead of focusing on aligning the business system objectives with the accounting package, many companies instead focus on fitting the business system into the accounting package. From the view of SMEs, this might be due to smaller firms having fewer skilled IT personnel who also have a good understanding of the business, employed to assist with strategic alignment (Cragg, King, \& Hussin, 2002). This results in the accounting package not being suitable for the management of the entity's entire business operations and failing to manage and deliver the required outputs the business requires.

Others further argue that in-house customisation of purchased accounting software packages is required to ensure that business strategies are managed and controlled by the same package (Olsen \& Sætre, 2007).

Newly established businesses face the challenge of selecting the correct accounting software package at the start of their business as well as the proper implementation of such package. This challenge is also faced by current businesses planning to replace or expand their current software. Part of this challenge is to successfully map business strategies at a strategic level with the functionalities of the considered generic accounting package before purchasing and implementing the software. This is to ensure that alignment of the considered accounting package and the business strategies will be possible. This process will identify areas where potential customisation during the implementation of the software might be required. During the accounting software-implementation process, software functionalities should therefore be properly aligned with the key business strategies to prevent future business system failure.

\subsection{Research Problem}

The drivers that enable an entity to attain its strategic goals and objectives, are referred to in this research as strategic business imperatives. The alignment of these strategic business imperatives and software functionalities is a common problem when it comes to the implementation of new ISs. This problem is also a reality of SMEs.

This research focused on one of the main constraints of successful strategic alignment of ISs within SMEs. Many SMEs implement generic accounting packages that do not provide all the functionalities that are required to achieve the entities' business strategies. Insufficient time and effort are invested by SMEs in the identification of their key business strategies and aligning them with the accounting systems they are considering implementing. It is essential for SMEs to spend the necessary time and resources in identifying accounting software packages that have the operational functionalities that will specifically address the key strategic drivers of the SMEs, before implementation.

However, this seldom happens within SMEs, as can be seen from the results of this research. Consequently, SMEs tend to install accounting software packages that do not have the operational functionalities to provide the required outputs for the business and fail to manage and drive their entire business operations. This results in business system failure and may result in the accounting package having to be replaced in the future. Many publications are available on addressing strategic IS alignment in general, but little is available that specifically focuses on guidance for SMEs. This research focused on addressing this challenge SMEs face when it comes to aligning their key business strategies with their accounting software systems.

\subsection{Research Objective and Scope}

The objectives of this research were to investigate the strategic business imperatives found within the business models which are common to SMEs and to identify accounting software functionalities that will be required to attain these strategic business imperatives and to do a mapping between these functionalities and drivers. This mapping highlighted required functionalities that are critical in the attainment of business strategies, but which might not be available from small generic accounting software packages. Accounting packages are becoming more and more important within the ISs of SMEs (Ismail \& King, 2007). Therefore, this is a valuable exercise to do for all SMEs implementing new accounting software packages, as this mapping will assist SMEs in preventing the implementation of incorrect accounting software that will ultimately lead to software failure. 
The above-mentioned mapping highlighted the strategic business areas that, if not addressed by the generic functionalities of small accounting packages, ultimately lead to failure of the business system. By identifying the business areas for which the accounting package will not be able to provide functionality, SMEs will be able to map the business requirements to the functionalities provided by the accounting package and address the shortcomings before implementation to prevent future business system failure.

It is important to note that during this research, not all possible strategic business imperatives were considered and discussed. Only some of the strategic business imperatives that were identified through the literature review in section 4.1 of this research and concluded to be relevant to SMEs were selected, and they do not cover the entire spectrum of strategic business imperatives. Due to the difference in nature between entities, all have different and unique combinations of strategic business imperatives. The purpose of discussing these strategic business imperatives was to provide management of SMEs with an overview of the results of misaligned software functionalities and their drivers.

\subsection{Research Organisational Structure}

This research consists of the following sections:

- Section 2 outlines the research approach that was followed throughout this research

- Section 3 contains a detailed literature review on the importance and relevance of strategic alignment for SMEs implementing new accounting software

- Section 4 presents a mapping that was developed between strategic business imperatives and the software functionalities that will be required by the small accounting package in order to attain these strategies.

- Section 5 presents the overview and outcomes of the research that was performed and also provides recommendations for potential future research in this field.

\section{RESEARCH METHODOLOGY}

A non-empirical approach was followed throughout this research. A literature review was conducted on various areas of the research problem by inspecting peer-reviewed and non-peer-reviewed academic articles with empirical content, published conference papers, theses and dissertations, white papers, popular articles, academic books and published frameworks.

Strategic alignment was firstly investigated by means of a literature review. During this review, specific focus was placed on defining strategic alignment and its implementation complications, furthered by its relevancy to SMEs.

In order to provide SMEs with an organised mapping between strategic business imperatives and software functionalities, the following methodology was followed:

- A literature review was performed on the strategic business imperatives commonly found within SMEs.

- The functionalities that might be required by an IS in order for an SME to successfully attain each of the identified strategic business imperatives were identified through a further literature review on case studies performed by different authors. For each of the business imperatives identified, an explanation is provided as to why small accounting packages might not have the functionalities to fulfil the strategic business imperatives.

- Information on a number of small generic software packages was inspected and available functionalities were identified. Although this sample was very small, the generic nature of accounting principles around the world provides reason for generic functionalities of accounting packages.

- For each of the strategic business imperatives and functionalities requirements, reasons are provided as to why it is important to have this functionality.

- Examples of potential business system failure are also provided should the accounting package be installed without the required functionalities.

- A mapping was performed between the strategic business imperatives and the software functionalities that will be required by the small accounting package in order to attain these strategies. 


\section{LITERATURE REVIEW}

Proper alignment of an entity's business strategies with its IT strategies is a necessity for entities to maintain a competitive advantage (Avison, Jones, Powell, \& Wilson, 2004) and to increase performance (Ismail \& King, 2007). A study conducted by Cragg et al. (2002) has concluded that small businesses that have strategic alignment perform better than businesses that do not. Other studies also found that entities tend to perform better when their ISs are aligned with their business strategies (Ismail \& King, 2007). It must be noted, however, that the operational environment of SMEs is very different from others and that the level of strategic alignment required for an SME might differ between different SMEs (Temtime et al., 2003). In a study conducted by Temtime et al. (2003:233) it was found that "SMEs tend to focus more on operational planning activities than on strategic planning activities".

\subsection{Information System Strategic Alignment}

Strategic alignment is found when the IS of an entity is sufficient to drive the business processes and simultaneously attain the strategic goals of the entity (Smit, 2009). For strategic alignment to occur, it is critical that the strategic business imperatives of an entity are identified and aligned with the IS of the entity.

\subsubsection{Business Imperatives and Basic Business Assumptions}

According to Goosen and Rudman (2013) it is important to understand the difference between business imperatives and basic business assumptions for sufficient alignment:

- Business imperatives: Kruger (2012) described business imperatives as those strategic objectives of an entity that are crucial for the entity to succeed. Strategic objectives necessary for an entity to achieve a competitive advantage above other entities are seen as its business imperatives (Goosen \& Rudman, 2013). Business imperatives can therefore be defined as those drivers of a business that enables the entity to attain its strategic goals and objectives. Due to each business having its own goals, business imperatives are therefor also unique to each business (Sahd \& Rudman, 2013).

- Basic business assumptions: The objectives of an entity that are required for an entity to operate on a daily basis are seen as its basic business assumptions (Goosen \& Rudman, 2013). These assumptions will not be sufficient for an entity to achieve a competitive advantage, but are necessary for an entity to operate as it should on a daily basis. These assumptions include inter alia accounting transactions, cash flow transactions, human resource and payroll transactions and transactions of all other business cycles (Boshoff, 2014).

\subsubsection{Information Technology Architecture}

For strategic alignment to be obtained, it is necessary that the IS of an entity drives both the basic business assumptions and the business imperatives of the entity. For this to be done, the business processes of an entity need to be properly managed by the IT set out in the IT architecture of the entity (Boshoff, 2014).

The IT architecture of an entity is a design that illustrates the requirements and specifications of the IT structure needed to align IT with the entity's business assumptions and business imperatives. Included in this architecture is the software application programs that will be installed. These software programs will have to be properly aligned with the basic business assumption requirements as well as the business imperative IT requirements in order to properly assist with alignment (Boshoff, 2014).

\subsubsection{Business System for Purposes of this Study}

Olugbode, Elbeltagi, Simmons and Biss (2008:11) describe a business system as all the tools, techniques and procedures that have to be used by an entity for data processing. The business processes of an entity include the processes that will be in place to manage both the basic business assumptions of an entity and its business imperatives. As a result, the IT architecture as discussed above sets out the IT requirements of an entity that will ultimately drive all the business processes of an entity. In this study, this is referred to as the 'business system' of a business. 


\subsubsection{Issue of Alignment}

In order for the IT architecture of an entity to successfully include all the IT requirements, it is important that the business system be properly aligned with its IT architecture (Boshoff, 2014). To support this, research conducted by Levy \& Powell, (2004) has shown that proper alignment between IT, business structures and processes and business strategies is very important for entities to succeed. During the process of alignment, business strategies are determined by the owners or top management. The business model and business processes are then built around these business strategies. In order for these business models and processes to be properly implemented, the IT personnel building the IT architecture will have to have sufficient knowledge of the business model and processes required (Levy \& Powell, 2004).

It often happens that the owners and top management do not have sufficient knowledge of or experience or interest in ISs (Levy, Powell, \& Yetton, 2001). Further to this, IT personnel do not always have sufficient knowledge of the business model and processes (Kruger, 2011). This results in the IT architecture, designed by the IS personnel, not being designed to address all the areas of the business system, especially the business imperatives. This creates an issue of alignment that ultimately leads to business system failure.

Figure 1 below illustrates the business system and the issue of alignment.

Figure 1. Illustration of a business system and the issue of alignment

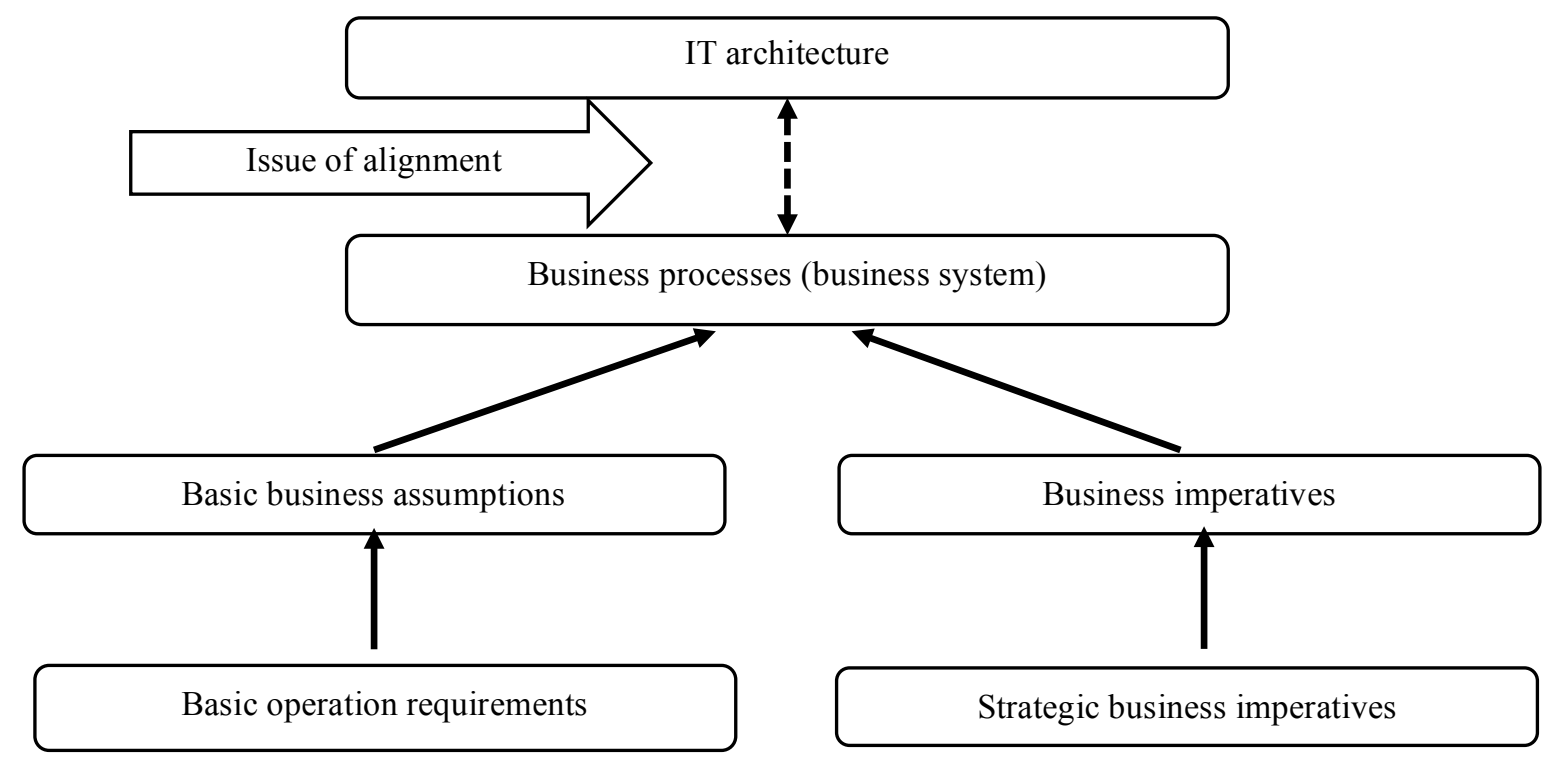

\subsection{Business System Failure}

Management of SMEs are normally the decision makers and involved in the implementation decisions of new software. Their IT knowledge will therefore contribute to the success or failure of the implementation process (Ismail \& King, 2007). It is often found that new technologies and software that are implemented fail before completion or are not in line with the expectations of top management (Griffith, Zammuto, \& Aiman-Smith, 1999). Whenever the IS of an entity fails to provide the outputs required by the user or does not function as required, it can be seen as IS failure (Dwivedi et al., 2015), ultimately leading to business system failure.

Accounting software packages form a key part in the IT architecture of SMEs and are also widely used by SMEs (Temtime et al., 2003). Many SMEs use accounting software packages to manage their entire business system. Managers of SMEs might also increasingly rely on management information provided by accounting software packages to assist them in their decision-making processes. Therefore, in situations where SMEs use accounting 
software packages to manage their business system, failure of the package to attain business imperatives will result in SMEs losing their competitive advantage and in the accounting package failing the businesses.

SMEs are struggling with aligning their application software packages with their business imperatives (Olatokun \& Kebonye, 2010; Webb \& Schlemmer, 2006). A study by Ismail and King (2007) on manufacturing SMEs in Malaysia indicated that the level of IT sophistication together with the IT knowledge of SME owners and management influences the capability of alignment and ultimately plays a role in business system failure.

The constraints of small accounting packages contributing to difficulty to align them with an entity's business imperatives include the limited functionalities they might have, as well as the level of customisation that is available on the software packages.

The following different types of software packages are available (Broida \& Flora, 2015):

- Generic software packages that are closed for any customisation requirements

- Generic software packages with availability for customisation, usually limited

- Custom-designed software packages.

\subsection{Strategic Alignment and Small and Medium-Sized Entities}

\subsubsection{The Scope of Small and Medium-Sized Entities}

Literature reviewed during this research varied on what was regarded as SMEs. The discussion below consequently provides information on the scope of SMEs that were included in this study:

- In the study by Ismail and King (2007) on Malaysian manufacturing firms, they define SMEs as entities with employee numbers varying between 20 and 150 employees. They mention that the most common SME indicator found by them was the number of employees, as internationally they found that not all SMEs are willing to disclose financial information.

- When considering the guidelines of South Africa's National Small Business Act (Act No. 102 of 1996), as cited by Kyobe (2004), entities with employee numbers of fewer than 100 are categorised as small or medium-sized entities. This was also the threshold Kyobe (2004) placed on the entities that were included in his research. He further narrowed his sample by looking at revenue numbers and asset values.

- In research conducted by Wynn (2009), the criteria of the Commission of the European Communities were used to select his sample. Accordingly, entities with no more than 250 employees, turnover levels at a maximum of 40 million euros per annum and annual asset values of a maximum of 27 million euros were defined as SMEs.

- SMEs that have adopted e-commerce technology in Botswana were researched by Olatokun and Kebonye (2010) and they varied in employee numbers of between 1 and 99 employees. A total of 120 SMEs were included in this research. These same criteria were also followed by Temtime et al. (2003) in a study on the strategic use of ISs in developing countries.

- In a study on small IT companies, Webb and Schlemmer (2006) followed the same criteria of the Commission of the European Communities by limiting SMEs included in their study to those with 250 employees. Their study was narrowed by only researching SMEs that were making use of online selling platforms.

In conclusion, SMEs covered in this study are entities with one or more of the following characteristics:

- Entities with a limited number of employees, and not exceeding 250

- Low turnover levels, not exceeding 40 million euros)

- Low asset values (not exceeding 27 million euros)

- Owner involvement at operational and decision-making level (Blili \& Raymond, 1993) 


\subsubsection{The Importance of Strategic Alignment for Small and Medium-Sized Entities}

SMEs provide the foundation of economies worldwide. Their contribution towards development in developing countries is exceptional (Amoako, 2013). In South Africa specifically, SMEs play an important role in poverty reduction and economy restructuring (Malefane, 2013). SMEs are seen as the force that drives the European Union economy (Matejun, 2014). It is also important to note that the issues SMEs have to deal with are in many aspects different to that of larger entities. SMEs are normally more owner-involved and strategies are developed from an owner's entrepreneurial perspective. They tend to have limited available financial and labour resources (Blili \& Raymond, 1993).

Many SMEs are therefore still finding themselves in the middle of deciding whether to continue with purchasing addon software and software expansions as their business grow or to invest in more sophisticated IT infrastructure due to the limited financial and staff resources available (Marcelino-Sádaba, Pérez-Ezcurdia, Echeverría Lazcano, \& Villanueva, 2014). Not investing in proper IT infrastructure results in SMEs having to deal with non-integration problems, insufficient information for management decision-making purposes and inability to effectively compete with other SMEs, especially those that are investing in e-business opportunities (Wynn, 2009).

Levy et al. (2001) found that SMEs are becoming more willing to invest in the development of their ISs in order to add value as the financial resources required to invest in ISs decrease. SMEs also tend to be sceptical about investing in system replacement due to the cost involved (Wynn, 2009). SMEs that are finding themselves in a growing phase are often required to replace or enlarge their ISs, as the original installed packages are not able to handle this growth. SMEs are sceptical of these types of investments (Levy \& Powell, 2004). Good customer relations are one of the features that enable growth within SMEs. It is, therefore, very important that the ISs implemented by SMEs contribute to maintaining good customer relations (Levy \& Powell, 2004). SMEs' investment patterns are also influenced by the strategies that they choose. Investment in ISs increases as the need to add value increases, while investment decreases among SMEs where cost-reduction strategies are present (Levy et al., 2001). A study conducted by Kyobe (2004) on SMEs in the eastern Free State province and part of the KwaZulu-Natal province of South Africa showed that some SMEs are using IT in an attempt to lower costs and improve their customer service. However, many managers are still not using IT strategically in reaching business imperatives. Examples are using IT to encourage innovation, linking systems to suppliers and product differentiation (Kyobe, 2004). It has long been seen that SMEs benefit from strategic alignment and IT development provides SMEs with the ability to be more innovative and as a result benefit competitively from it (Blili \& Raymond, 1993).

\subsubsection{Issues of Strategic Alignment within Small and Medium-Sized Entities}

The owners of SMEs, who are often the key decision makers, need to identify and drive the implementation of ISs. As discussed earlier, owner involvement in IS implementation is critical for proper alignment between the business system and IS architecture. Having the owner involved in this process contributes to better alignment (Levy \& Powell, 2004).

As mentioned before, owners of SMEs do not always have sufficient knowledge of IT, thereby constraining the issue of alignment. In addition, many SMEs do not have their own IT department and have to rely on IT consultants (Levy \& Powell, 2004). The challenge for SMEs in this respect is to use IT consultants that are highly skilled and specialised in their field, but also understand the business model and strategies of the specific SME. It is therefore critical for owners of SMEs to make use of professional, skilled IT consultants when aligning the IT architecture with their business system.

At the time of this research, SMEs were still struggling with the proper alignment of IT architecture with their business systems (Kyobe, Namirembe, \& Shongwe, 2015). Figure 2.2 illustrates some of the positive and negative influences SMEs are facing when implementing new software. 
Figure 2. Positive and negative influences of information system adoption in SMEs

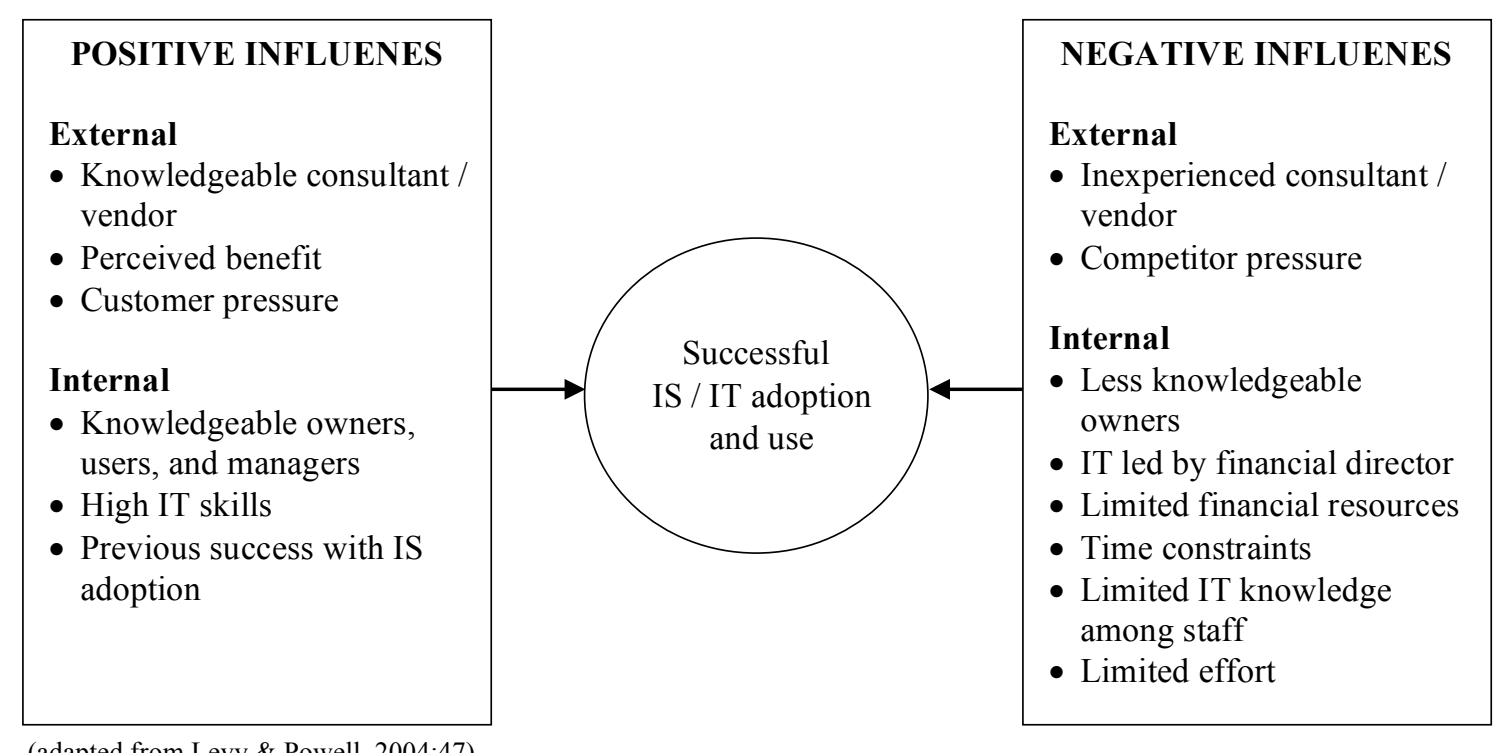

\section{MAPPING OF BUSINESS IMPERATIVES WITH ACCOUNTING SOFTWARE FUNCTIONALITIES}

In a study conducted by Pulakanam and Suraweera (2010), it was found that SMEs are often in a position where the accounting package implemented does not meet their requirements. In order to prevent failure of accounting software used by SMEs as their business system, it is important that these accounting software packages, and specifically the functionalities they provide, are properly mapped to the business imperatives of the specific SME. Accounting software packages should only be purchased if the functionalities that they provide meet the needs of the SME, but is still affordable.

Software integration problems are experienced by SMEs (Pulakanam \& Suraweera, 2010). It happens, for example, that SMEs have developed websites that are not integrated with their accounting software (Levy et al., 2001). SMEs are starting to use web-based software applications more often due to these being easy to use and available at more affordable prices (Azyabi et al., 2014). When websites are used to drive a large portion of the (if not the entire) business, it is critical that transactions captured on the websites are sufficiently integrated with the processing thereof. Compatibility and integration of accounting software with websites are critical for these types of SMEs to prevent the business system from failing in the delivery of required information. Furthermore, when purchasing and implementing accounting software, it is often seen that SMEs invest in software that brings improved production, but lacks integration with the accounting software (Levy et al., 2001).

A literature review on business imperatives, commonly seen to be strived towards by SMEs, was conducted to determine the focus of this study.

\subsection{Business Imperatives of SMEs}

Cragg et al. (2002:114) investigated nine potential business strategies applicable to SMEs to identify the level of importance these strategies had for the firms and also whether these strategies were supported by the IT system of the firms. These nine strategies are: pricing, quality product, product differentiation, product diversification, new product, new market, quality service, intensive marketing and process efficiency. Process efficiency, quality service and quality product were identified as the most important strategies for SMEs and were also found to be mostly supported by the IT systems of the firms, while product differentiation, new markets and product diversification were identified to be strategies SMEs view as important, but that were not supported sufficiently by their IT systems and consequently 
resulted in IT misalignment (Cragg et al., 2002:124). As a result, process efficiency, quality service/product, product differentiation, diversification and new products and markets were selected as part of the business imperatives investigated during this research.

Further to these selected strategies, low cost (Lesjak, 2000; Levy et al., 2001; Umble, Haft, \& Umble, 2003), innovation (Hussin, King, \& Cragg, 2002; Olsen \& Saetre, 2007), mobility (Park, 2015), pro-active management (Levy et al., 2001), de-skilled workforce (Azyabi et al., 2014) and customer-centric (Cragg et al., 2002) were also investigated due to its relevance to SMEs as identified by other research. De-skilled workforce are defined as employees who are involved in the performing of certain tasks for which they are not properly trained for (Azyabi et al., 2014).

It is also said that SMEs with business strategies of either low cost or adding value to the product, service (quality product/service) or processes tend to be more successful in the investment of their ISs. Low-cost strategies are typically followed by SMEs where ISs do not play a large role in the business and where the owner's IT knowledge is mostly limited. Accounting software in these SMEs are mainly used for transaction processing. SMEs striving towards a more value-adding business model are seen to be more innovative in their IT investment with greater focus on the availability of information used by management for decision making (Levy et al., 2001).

The focus-dominance model was developed by Levy et al. in 2001, after analysing 27 SMEs. This model concludes that SMEs' business imperatives strongly influence the software that SMEs invest in or have to invest in. The business imperative identified by this model that affects SMEs is a low-cost approach versus the delivery of value-adding services, being a service of better quality. It is illustrated by this model that the number of customers is also a contributing factor to the level of software investment by SMEs (Levy et al., 2001). Four different competitive environments were further identified by taking the level of business imperative focus and number of customers into account. These are efficiency, coordination, collaboration and innovation.

The figure below illustrates how software investment is influenced by the business imperatives and number of customers of SMEs.

Figure 3. Information systems mapped in accordance with the focus-dominance model

\begin{tabular}{|c|c|c|c|}
\hline \multirow{3}{*}{$\begin{array}{l}\text { Number of } \\
\text { customers }\end{array}$} & Low & $\begin{array}{l}\text { Coordination } \\
\text { Word processing } \\
\text { Accounting } \\
\text { Customer databases }\end{array}$ & $\begin{array}{l}\text { Innovation } \\
\text { Word processing } \\
\text { Accounting } \\
\text { Electronic business }\end{array}$ \\
\hline & High & $\begin{array}{l}\text { Efficiency } \\
\text { Word processing } \\
\text { Accounting }\end{array}$ & $\begin{array}{l}\text { Collaboration } \\
\text { Word processing } \\
\text { Accounting } \\
\text { Materials requirements } \\
\text { planning } \\
\text { Electronic data } \\
\text { interchange } \\
\text { Collaboration }\end{array}$ \\
\hline & & \multicolumn{2}{|c|}{$\begin{array}{l}\text { Low-cost } \quad \text { Value added } \\
\text { Strategic business imperatives }\end{array}$} \\
\hline
\end{tabular}

The model above was partially used as a framework during this research for the positioning of an SME based on its business imperatives. The positioning of an SME within this model provided more clarity on the type of software that the SME requires to achieve its business imperatives and was used to identify the respective software functionalities required. 


\subsubsection{Features of the Focus-Dominance Model}

SMEs finding themselves in the efficiency quadrant view investment in software as a cost rather than an investment and strive to keep cost as low as possible. These SMEs are focused on improving the efficiency of their business processes (including the use of word-processing systems and accounting software) in order to service the higher customer demand (Levy et al., 2001).

In the coordination quadrant, SMEs focus highly on the maintenance of their customer relationships. The communication between the SMEs and their customers becomes more important, and, consequently, the IT architecture is the driver of effective communication. Low cost is, however, also a important factor in this quadrant (Levy et al., 2001).

The collaboration quadrant is where SMEs focus on cost-effectiveness rather than low cost. Data exchanges between these SMEs and customers are found and therefore software is used in a more sophisticated manner. These SMEs strive to add value through their software investments by generating appropriate information for communication with customers (Levy et al., 2001).

The software of SMEs in the innovation quadrant plays an integral part in the attainment of their business imperatives. These SMSs are very often found in an electronic business environment (Levy et al., 2001). such as small and mediumsized digital enterprises (Levy et al., 2001). Digital enterprises are entities that mainly uses digital resources to deliver services to its clients and constantly monitors new digital enhancements that will add value to service delivery (Bērziša et al., 2015).

\subsection{Functionalities}

The functionalities of accounting software packages can be seen as the functions that are available to the users in order to reach the required business imperatives (Kruger, 2012). These include inter alia the input and output requirements that are needed for the generation of accurate financial reports for external reporting and accurate management accounting reports for internal decision-making.

Functionalities, as set out in an entity's IT architecture, can be divided into those required to reach basic business assumptions and those that drive business imperatives, as discussed in Chapter 2.

Based on a review of a number of small generic accounting packages, it was found that, due to the generic nature of accounting principles around the world, these packages typically provide the following functionalities:

- Automatic generation of general ledger

- Accounts receivable and payable

- Invoicing

- Trading in alternative currencies

- Sales order generation

- Expense and profit tracking

- Inventory control and bills of material (some accounting software has this as add-on software)

- Production planning and control

- Multi-user access (often limited to low employee numbers)

- Cost accounting and management accounting reports

- Basic financial reports, including income statements and balance sheets.

The above functionalities are needed mainly to drive the basic business assumptions. These functionalities are not always sufficient to attain the business imperatives of the SME. Therefore, it is critical that other functionalities not typically available in small accounting packages also be investigated before implementation to ensure that the functionalities that need to drive the business are available or are added either through customisation or other sources. 
A number of small accounting packages were also investigated, typically designed for specific industries, to identify other functionalities not included in generic packages. These functionalities include:

- Integration with other software packages

- Web-based platform ability/integration

- Real-time updating of information on different devices

- Booking management and integration

- Pre-defined and simple workflow

- Remote access

- Bills of materials (if not part of the basic accounting package).

\subsection{Business Imperatives and Required Functionalities}

Based on the literature review reported on in Section 4.1 and 4.2, business imperatives applicable to SMEs were identified together with the required software functionalities that they might require in the attainment of these business imperatives. These functionalities were then compared to the functionalities typically provided by small accounting packages in the sections below.

\subsubsection{Low Cost}

Most SMEs find themselves in a competitive environment in which, to survive, they need to reduce costs as far as possible. Increased competition between companies adds pressure on businesses to lower costs on all possible levels (Umble et al., 2003). Some SMEs still view investment in software as a cost rather than an investment (Levy et al., 2001). Entities with low cost as a business imperative tend not to use their ISs in a strategic way (Lesjak, 2000) due to the potential costs involved. Small businesses might prefer to buy the basic versions of generic accounting software packages for implementation rather than spending on the more advanced versions or the development/customisation of software. Both software development and software customisation also require a highly skilled IT workforce, which is expensive and not ideal for businesses striving towards lowering costs. Even SMEs adopting enterprise resource planning (ERP) systems sometimes do not have the same availability of financial resources as larger entities, resulting in scaled-down implementation (Muscatello, Small, \& Chen, 2003). The same can be said of SMEs implementing generic accounting software to act as their business system. Due to the limitation of financial resources, SMEs might prefer to implement only the basic software, rather than spending on the development of the software to enable them to reach their business imperatives. The customisation of software might be necessary for a SME to successfully use the accounting software as a business system that drives the entire business and its imperatives.

As a result of the above issues, software bought by an entity does not necessarily provide the desired functionalities and requires extensive customisation and development for it to work for the business (Kruger, 2012). Some entities do not want to spend the time and money required for these developments and customisations and often, after realising that the cheaper package is failing them, continue to buy a more expensive package that is more suitable for the business or other add-on software that provides the required missing functionalities. Buying the lowest-cost software results in having to spend more in the long run to compensate for missing functionalities. Investing in the development or customisation of purchased accounting software at the start may prove to be more cost-effective. Thus, SMEs investing in lower-cost accounting packages may find themselves spending more in future periods. Implementing packages that fail to drive the business system results in the entire IS failing. Therefore, investing in the lowest-costing software does not necessarily assist in the attainment of a low-cost strategy.

\subsubsection{Functionalities Required in a Low-Cost Environment}

SMEs that strive towards improving efficiency, while, at the same time, keeping costs to the minimum, should focus on the functionalities that will enable the organisation to be operated successfully without requiring too many modifications to the software or capital investment. In this regard, the following recommendations can be made: 
- The accounting software should be able to accommodate the number of users that are assigned to work on the accounting software. Usually with smaller versions of accounting packages, the user counts are limited, which may contribute to inefficiencies if more users are required to obtain access to the software but cannot.

- It is also seen in lower-cost environments that manual processes and systems, such as spreadsheets, are used in conjunction with accounting software such as payroll, invoicing systems and general ledger transactions (Levy et al., 2001). It is, therefore, critical that the various accounting packages are properly integrated so that data transfer and data sharing are possible.

- The software must manage the customer database and handle an increase in customers, especially if it is a start-up SME that has the potential to grow.

- Ease-of-use input interfaces should be available to assist employees, who might not always be properly trained, to easily record data that are kept manually.

\subsubsection{Consequences of Lack of Available Functionalities:}

- $\quad$ Non-integration of different small software packages, leading to inefficient operations

- Incomplete accounting records due to the inability of software packages to share data

- Inability to manually manage the customer database in the event of increases in situations where the system is not able to handle the amount of customers. This can lead to incomplete/incorrect customer information and may have a negative effect on customer relations.

\subsubsection{Innovation (Including New Products)}

As mentioned in section 3.3.2, for SMEs to maintain a competitive advantage above others, innovation plays a key role, especially when entering new markets or launching new products. For SMEs to be innovative, the optimal use of IT becomes essential. Olsen and Sætre (2007) are of the opinion that some SMEs regard innovation as one of their survival strategies. Innovative entities are also more often seen to have ISs aligned with their business strategies than other non-innovative entities (Hussin et al., 2002).

A case study conducted by Yetton, Johnston and Craig (1994) on an architectural firm showed the importance of IT for firms to enable them to provide the best services to their clients. Firms that are similar in nature, for example architectural firms, are required to constantly deliver new and top-of-the-range products to successfully compete with similar firms in the market (Smit, 2009). It is further argued that SMEs that embrace technological development tend to gain more than SMEs that do not (Blili \& Raymond, 1993). IT therefore becomes critical when it comes to innovative strategies (Levy et al., 2001).

Basic versions of generic accounting software packages purchased by SMEs seldom have all the functionalities available to drive innovation. Taking the example of an architectural firm above, generic accounting software is not specifically tailored to manage all the data of an architectural firm. Architects typically make use of specialised software on which drawings and designs for client orders are done. These design programs are run separately from the accounting software on which quotations, orders and sales are processed and are therefore not always integrated. Some might argue that it is not necessary for these two types of programs to be integrated, because the accounting software assists with account processing, while the architectural design software assists in developing the end products. However, for a quotation and invoice to be generated, the cost of the job needs to be calculated accurately. For this to be done, the details of the resources used in the design are required, by using the architectural software, in other words architectural hours spent on the job and the scope of the work being done. Some architectural software might have the functionality to keep track of the hours spent on a job and the resources utilised, while others might not. In scenarios where the software does not keep track of the hours spent, another software management system might be purchased to assist in this regard, contributing to a third software program that again does not necessarily integrate with the other software program used by the entity. It is imperative that the costing of a job/products is calculated correctly, as it directly affects the profitability of an entity. 
In the study by Levy et al. (2001), one of the innovative types of entities had used its core design program to manage its business processes. The entity had a website and allowed for online orders by customers. The challenge faced by this entity was to link designs to orders and to integrate the order-generation software with its accounting software (Levy et al., 2001). Innovative SMEs are therefore striving towards adding customer value through the use of their IT systems.

\subsubsection{Functionalities Required for Innovation}

The required functionalities to enhance innovation as a business imperative in SMEs and add value include, among others, the following:

- Accounting software packages should be integrated with non-accounting software packages (design, operational and other add-on software) that enable data transfer and data sharing (Levy et al., 2001). An area that still causes major frustrations for SMEs is the non-integration of their various software packages (Pulakanam \& Suraweera, 2010). Due to small accounting packages having limits in terms of the level of customisation allowed by users, the integration of the software with other packages is often not possible.

- Web-based platform ability for customer order generation, marketing, communication and customer support should be created to enable good customer service to clients. Customer service is seen as important for SMEs to maintain a competitive advantage (Cragg et al., 2002). Not all small accounting package versions provide the functionality to integrate web-based order processing with the accounting system. Orders generated on a web-based platform should be integrated with accounting packages to enable complete and accurate invoice generation.

- Efficient online customer support is a key functionality that enables SMEs to build customer relations. Online support can add value if relevant information on customer data is available to customers online, such as transaction details and statements. Customer information should also be accessible to customer support staff to easily assist customers with enquiries (Boshoff, 2014).

\subsubsection{Consequences of Lack of Available Functionalities}

- Non-integration between website data and accounting software data

- Duplication of missing orders due to orders not being linked to accounting software, leading to incomplete financial figures

- Inaccurate cost calculations (job costs, design costs, etc.), resulting in inaccurate invoices

- Decrease in customer satisfaction should information not be available to customers.

Should the above-mentioned consequences not be identified at the start of the implementation project, it will lead to failure of the business system (Kruger, 2012) to attain innovation in the entity.

\subsubsection{Possible Solutions to Lack of Functionalities}

Non-integration of software programs can be solved by either introducing manual systems or customising accounting software. The latter is the more expensive alternative and also the alternative rarely taken up by SMEs. Manual intervention, on the other hand, can result in additional labour resource requirements together with the risks of human error.

\subsubsection{Product/Service/Business Diversification (Including Reference to New Markets)}

The diversity of businesses is driven by the different types of products they supply and services they render. In a study conducted by Hussin et al. (2002), product diversification formed part of the IT strategies followed by many SMEs. The more diverse businesses are, the more flexibility they require from their business processing systems and the more the need for amending or adding functionality becomes a requirement. The importance of flexibility for SMEs in order to gain a competitive advantage is discussed by authors such as Olsen and Sætre (2007). The effectiveness of the 
business processes of SMEs is very dependent on flexibility. The quality of the products and services of SMEs as well as flexibility is regarded as important for market strategy and innovation (Matejun, 2014).

Small generic accounting packages are not always flexible enough to allow for diverse product/service ranges. In addition, the customisation potential of the software package functionalities is also limited (Olsen \& Sætre, 2007). This can result in businesses amending their unique processes to fit the purchased software rather than customising the software to fit the business needs. It can also result in SMEs purchasing other software packages that will assist in managing the functionalities not addressed by the accounting software invested in, which may lead to non-integration between the different packages.

SMEs striving towards diversity will find themselves delivering various types of products and/or services, which may be all in different markets. The challenge with diversification in SMEs is to find an accounting package that is flexible enough to accommodate all the different service and product types.

\subsubsection{Functionalities Required for Diverse Businesses}

The functionalities that will be required to enable diverse businesses are extremely wide and will be dependent on the different products and services. The most important need is that the software functionalities must be adaptable for the requirements of the specific SME. A few examples are listed below:

- The software must have the ability to create different inventory and service types and/or accommodate different income streams or business divisions. Basic versions of accounting packages might limit the number of different income streams or divisions and it is important that a package be selected that can manage these.

- The software must offer bills of materials set-ups for different types of inventory, especially in small and medium-sized manufacturing entities. Some types of small accounting software do not have the functionality to manage bills of materials and add-on software that provides this functionality must be purchased separately.

\subsubsection{Consequences of Lack of Available Functionalities}

- Not purchasing the bills of materials add-on functionality can result in inaccurate stock valuations and inability to effectively manage inventory, resulting in consequent failure of the inventory system.

- The inability of software programs to handle different income and products streams can lead to inefficiency of business processes.

- Incorrect financial information due to the non-integration of different income streams.

\subsubsection{Product/Service Differentiation}

Based on the study by Hussin et al. (2002) it is evident that differentiation of products and services is also important for some SMEs, especially for SMEs that are finding themselves in a competitive environment. These SMEs would strive towards the delivery of products and services that are better than that of their competitors (Alvarez \& Iske, 2015) and therefore product quality becomes an important focus (Cragg et al., 2002). In order for SMEs to differentiate themselves from their competitors, innovation and/or collaboration becomes an important strategic focus (Alvarez \& Iske, 2015).

\subsubsection{Functionalities Required for Product/Service Differentiation}

- SMEs using different types of software programs on which to differentiate their products or services would require for those software programs to properly integrate with the accounting software used.

- Web-based platform ability should be available for the more innovative SMEs that are using websites and e-commerce functionalities to differentiate themselves from their competitors. Accounting software requires functionalities that can integrate with websites to enable order placement and invoice generation. 
- Customer data should be available to customers online to provide quality services to clients.

- The accounting software should have an effective inventory control system and related quality reports that can be used by management to control the quality of products that are manufactured or supplied to clients.

\subsubsection{Consequence of Lack of Available Functionalities}

Insufficient product quality information can directly affect the quality of the product and services rendered and affect the differentiation of the product or service rendered by the SME.

\subsubsection{Mobility}

Hislop (2008) mentions in his book, Mobility and technology in the workplace, how the continued use of mobile technology significantly contributes to change in the traditional workplace to a more mobile environment. He also concludes that the modern worker is still constantly facing the challenges of reacting to the failure of technological systems. SMEs are also facing the challenge of mobility and how mobile technology is increasingly used in the business (Park, 2015).

SMEs that strive towards a more mobile environment will likely have innovation as a business imperative. ISs are used to add value to the business (Levy et al., 2001) and provide appropriate information to customers. Access to company information when visiting and communicating with customers is required by these types of SMEs.

Operation managers and fieldworkers also require timely information on production to assist them with effective decision making. ERP systems are used by many large companies to enable them to obtain relevant information timeously. These systems are however still too expensive for SMEs to invest in. The collection of production data through mobile resources is becoming increasingly attractive to SMEs. Web applications and mobile applications are available to SMEs to remotely access production information (Park, 2015).

\subsubsection{Functionalities Required for Mobility}

Required functionalities to enhance mobility in SMEs include the following:

- Remote access to accounting software information through internet access, either via desktop, laptop or tablet applications, is a requirement. Not all basic accounting software packages have the functionality of remote access, which might be crucial for sales teams and other employees needing to access accounting data from mobile or other devices. Many small accounting packages do however allow for access via remote desktop through a virtual private network.

- Security and protection against fraudulent data access. Most small accounting packages have the functionality of creating different user groups and user profiles that manage unauthorised access. This should however be configured during the implementation stage of the software packages. User groups and user profiles are however not sufficient to prevent unauthorised users from accessing company information. Proper security programs have to be purchased and installed together with the accounting software to prevent unauthorised access. These security programs should be integrated with accounting software to enable efficient security features.

- Multiple user access is required for different employees to access accounting software. Based on a review conducted by this research on the functionalities of a number of small generic accounting, it was found that user access is in many cases limited to low user numbers and that additional licence fees have to be paid for additional users.

- The integration and data sharing between accounting software and of mobile apps or web applications are crucial for operation managers of manufacturing SMEs that want to remotely access production data for effective decision making. 


\subsubsection{Consequences of Lack of Available Functionalities}

- Slow connections through remote desktops lead to inefficiency of employees performing daily tasks, ultimately leading to company losses

- Inability of employees to access information from anywhere

- Unauthorised access to company data and information

- No access to software for additional users should the allowed user numbers be reached

- Inability of operation managers of manufacturing SMEs to effectively and timely make operational decisions if production data are not available.

\subsubsection{Pro-Active Management}

Innovative SMEs using mobile applications, as discussed above, can also be seen as being pro-active when it comes to management and decision making. To be pro-active in managing a business it is key to have real-time information available at all times, especially when it comes to decision making (Goosen, 2012). Accounting software packages require functionalities to provide real-time information to management and staff on a continuous basis. Due to the increased competition SMEs are facing and the availability of new technologies, SMEs are increasingly investing in ISs that promise to increase efficiency and enhance pro-active management through inter alia the availability of realtime data (Seethamraju, 2014). Although many software packages have the ability to provide reports, these reports are mainly generic and do not necessarily provide the required real-time information that each business requires at particular times.

SMEs striving towards being pro-active in their strategic approach are those that realise the importance of good management information in their decision-making processes. In one of the collaboration case studies conducted by Levy et al. (2001), the SMEs found that they are losing their competitiveness due to poor management information and information only becoming available several months after it was processed. In this specific case, the company was also situated over various cities, which resulted in information and data being available at different locations.

\subsubsection{Functionalities Required for Pro-Active Management}

Required functionalities to enhance pro-active management in SMEs include the following:

- Real-time information should be available to managers that are using information to make decisions. This implies that the accounting software should have the functionality where appropriate information is generated at any given time, either via reports or graphs. Not all small accounting software have the functionality of instantly being able to provide management information.

- Data and information from various locations should be available through internet access and/or local area networks. This enables managers to access information and data when SMEs are situated at various locations. It must be possible to install the accounting software at different premises and to share data from a main server if it is used as the business processing system.

\subsubsection{Consequences of Lack of Available Functionalities}

- Should data and information not be available at all the locations of the entity, it can lead to inefficient working environments and incorrect decision making.

- Data not being available to management when they require them for important decision-making purposes will lead to incorrect decision making.

\subsubsection{De-Skilled Workforce}

Due to SMEs having a smaller workforce than larger entities, employees tend to be involved in many tasks that require different skills (Azyabi et al., 2014). It can therefore happen that employees are involved in the performing of certain 
tasks for which they are not properly trained. In situations such as these it is crucial that the accounting software used by these employees is easy to use with a simple workflow (Boshoff, 2014).

SMEs with a de-skilled workforce are typically SMEs with a low-cost strategic approach where multiple customers are being served. In the efficiency case study of Levy et al. (2001) it was found that a small off-the-shelf accounting package is used by the SME to improve efficiency while at the same time striving to keep costs low.

\subsubsection{Functionality Required for a De-Skilled Workforce}

The required functionality to enable de-skilled employees to operate accounting software includes the following:

Pre-defined and simple workflow interfaces are required for ease of use by employees. Accounting software packages need to be automated as far as possible to limit inputs from users to the absolute minimum in an effort to limit any inefficiencies as a result of de-skilled users. Small accounting packages tend to have simple and easy-to-use platforms with pre-defined workflow functionalities. It is however important to configure pre-defined workflows at the implementation phase of software to prevent future failure.

\subsubsection{Consequence of Lack of Available Functionalities}

The lack of pre-defined and simple work-flow interfaces can lead to inefficiencies due to users not knowing how to operate the system. It may also lead to the input of incorrect data, resulting in incorrect financial information. On the other hand, it should also be noted that pre-defined and simple work-flow, can also result is decreased flexibility.

\subsubsection{Customer-Centric Strategy}

One of the key strategies found within SMEs in which to maintain a competitive advantage is customer service (Cragg et al., 2002). It is often found that SMEs have a few large customers who contribute to high portions of the total income received by the SMEs. SMEs are dependent on these customers and their focus is to have and maintain good customer relations.

In a case study by Levy et al. (2001) of an SME in the coordination quadrant, insufficient controls and the informal ways of dealing with its clients led to incomplete accounting data and lack of follow-up on client information and requests.

\subsubsection{Functionalities Required for Customer-Centric Strategy}

SMEs striving towards being customer-centric pride themselves in the personal services they render to their clients. Continuous communication and feedback to their clients are important for reaching this goal. Functionalities required to achieve these are the following:

- A user-friendly web-based information platform for the innovative type of SMEs is required that enables customers to gain access to product or order information. Integration with accounting software and these webpages should be possible.

- Access to customer account information should be available to all employees directly communicating with customers to enable them to provide customers with relevant and correct information. Accounting software should therefore provide user access to these employees.

\subsubsection{Consequences of Lack of Available Functionalities}

- Unhappy customers not receiving the desired service expected.

- Loss in competitiveness. 


\subsubsection{Process Efficiency}

Efficiency has been identified by Levy et al. (2001) and Cragg et al. (2002) as business imperatives of many SMEs. SMEs striving towards efficiency will want their business processing system to contribute to the efficiency of all their processes.

An example is SMEs that make use of booking systems to manage their clients. They require an IS that can both initiate a booking and create an order that will, after service delivery, be an instruction for the creation of an invoice. This whole process should be efficiently driven by the accounting software that is installed. The inability of small accounting software to manage bookings can result in the SME manually having to transform bookings into invoices. Customisation of the accounting packages to integrate with the booking system might however be a more efficient approach to follow. Olsen and Sætre (2007) argue that SMEs must be in control of the customisation of software functionalities to provide them with a competitive advantage. Furthermore, customisation of software is said to be possible at much lower costs than in the past (Olsen \& Sætre, 2007).

Effective stock control systems are also a requirement for manufacturing SMEs that strive towards process efficiency (Park, 2015).

\subsubsection{Functionalities Required to Enhance Process Efficiency}

The required functionalities to enhance process efficiency are as follows:

- Functionalities to manage booking and reservation systems should be available in the order- and invoicegeneration processes. Businesses that might use these include guest houses, boutique hotels, hair salons and other service-rendering SMEs. Booking software systems are available for service-delivery companies. Some even have the functionality of point-of-sale, invoicing and online payments. Functionalities required in these instances include generating, tracking and invoicing of bookings. SMEs not investing in proper booking software systems that generate accurate financial results, but rather making use of generic accounting software systems to account for their service transactions, might be faced with non-integration issues between the booking system in use and the accounting software generating the financial results, leading to failure of the entire business processing system.

- Real-time information should be accessible by operation managers and other employees to enable them to efficiently react on service requests.

\subsubsection{Consequences of Lack of Available Functionalities}

- Non-integration of booking/reservation software and accounting software

- Bookings not being invoiced for, leading to incomplete accounting information

- Inability to instantly making decisions if real-time information is not available.

\subsection{Mapping of Business Imperatives with Software Functionalities}

Business imperatives discussed above and functionalities that might be required to attain them are listed in the table below: 
Table 1. Business imperatives mapping table

\begin{tabular}{|c|c|c|c|c|c|c|c|c|c|}
\hline & & & & Bus & $\mathrm{imp}$ & ives & & & \\
\hline & $\begin{array}{l}0 \\
0 \\
0 \\
0 \\
0 \\
0 \\
3\end{array}$ & 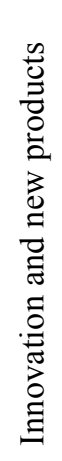 & 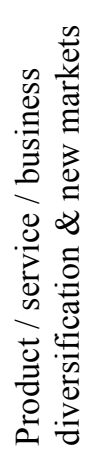 & 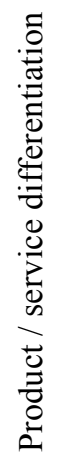 & 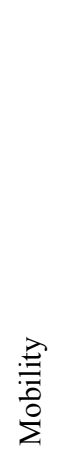 & 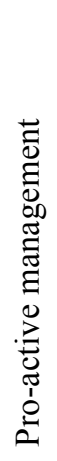 & 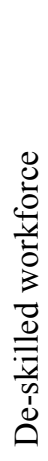 & 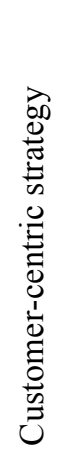 & 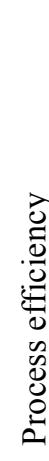 \\
\hline $\begin{array}{l}\text { Accommodation of number of } \\
\text { users }\end{array}$ & $\mathrm{X}$ & & & & $\mathrm{X}$ & & & $\mathrm{X}$ & \\
\hline Software package integration & $\mathrm{X}$ & $\mathrm{X}$ & & $\mathrm{X}$ & $\mathrm{X}$ & & & & $\mathrm{X}$ \\
\hline $\begin{array}{l}\text { Customer database } \\
\text { management }\end{array}$ & $\mathrm{X}$ & & & & & & & & \\
\hline Ease-of-use interfaces & $\mathrm{X}$ & & & & & & $\mathrm{X}$ & & \\
\hline $\begin{array}{l}\text { Web-based platform } \\
\text { availability }\end{array}$ & & $\mathrm{X}$ & & $\mathrm{X}$ & & & & $\mathrm{X}$ & \\
\hline Online customer support & & $\mathrm{X}$ & & $\mathrm{X}$ & & & & & \\
\hline $\begin{array}{l}\text { Accommodate different } \\
\text { product and income streams }\end{array}$ & & & $\mathrm{X}$ & & & & & & \\
\hline $\begin{array}{l}\text { Bills of materials and } \\
\text { inventory management }\end{array}$ & & & $\mathrm{X}$ & $\mathrm{X}$ & & & & & \\
\hline Remote access & & & & & $\mathrm{X}$ & $\mathrm{X}$ & & & \\
\hline Security and protection & & & & & $\mathrm{X}$ & & & & \\
\hline Real-time information & & & & & & $\mathrm{X}$ & & & $\mathrm{X}$ \\
\hline
\end{tabular}

Key: $\mathrm{X}=$ Functionalities that might be a requirement for SMEs to attain their business imperatives

\section{CONCLUSION}

Many publications are available on strategic alignment of ISs and business strategies of large entities. This topic has already been widely researched in order to narrow the gap between ISs and business strategies. Many recommendations and frameworks have been developed to assist entities in narrowing this. Little, however, has been developed on the tools and frameworks available to SMEs during software implementation and specifically the challenges they face when implementing software. In addition to facing challenges similar to those of larger entities with regard to software implementation, SMEs are also challenged by other obstacles such as limited skilled staff and resources due to their size (Marcelino-Sádaba et al., 2014), high costs relating to software implementation and competition in the SME market.

This study focused on the strategic alignment of ISs within SMEs and identified strategic misalignment as one of the main reasons why SMEs fail to properly implement accounting software.

\subsection{Results from the Literature Review on Strategic Alignment within Small and Medium-Sized Entities}

A literature review was performed on strategic alignment between business strategies and ISs, in which strategic alignment and its importance in the prevention of software failure were investigated. This literature review also 
focused on the relevance of strategic alignment for SMEs specifically. Based on this review, it was concluded that strategic alignment is very important for SMEs to attain a competitive advantage in the industry and to prevent their ISs from business system failure. It was further concluded that strategic alignment is just as important for SMEs as it is for larger entities. The challenges faced by SMEs include correct alignment of their IT architecture with their business model and processes. Knowledgeable individuals are to be involved in this alignment process and alignment should be embraced by the owners of SMEs.

In order for SMEs to successfully align their IT architecture with their business model and processes, business imperatives need to be clearly identified and aligned with software applications included in the IT architecture. This whole process should be properly managed and controlled so that the requirements of management are reflected by the implemented IS.

\subsection{Results from the Mapping of Business Imperative and Software Functionalities}

Mainly due to the high cost implications of software programs, SMEs often fail to implement accounting software packages that will successfully deliver the outputs to drive the entire business by simply selecting a generic software package that does not provide the functionalities the SMEs require to manage their business processes.

A literature review was performed to identify the business imperatives commonly found within SMEs. For each of these business imperatives, software functionalities were identified that will be required in order for SMEs to attain the specific business imperative. It is important to note that during this research, not all possible strategic business imperatives were considered and discussed. Only some of the strategic business imperatives that were found to be most commonly relevant to SMEs were selected, and they do not cover the entire spectrum of strategic business imperatives.

A mapping table was developed that maps the most common business imperatives followed by SMEs with the software functionality that might be required in order for the SMEs to attain their business imperatives.

Business imperatives identified through a literature study included low cost, innovation and new products, diversification and new markets, differentiation, mobility, pro-active management, de-skilled workforce, customercentric strategy and process efficiency. The focus-dominance model developed by Levy et al., (2001) was used to determine the potential software functionalities that will be required from the implemented accounting package. These functionalities include integration ability, the level of complexity of operating the software, electronic capability and availability for customisation.

From the literature review and mapping table it was found that, in order for a SME to select the correct accounting software package, it is important to invest time and effort in considering the software functionalities provided by the software package and mapping these with the business imperatives that drive the SME. Not all generic accounting software packages provide these functionalities and it might be necessary to invest in either a more advanced package or customise. In order for SMEs to properly map their business imperatives with required software functionalities and ultimately decide on the correct software package, a high level of insight and planning is required. If a generic software accounting package is installed that does not provide these outputs, it will result in software failure.

Ultimately, the time, cost and effort involved in selecting the best accounting software package will prove to be beneficial in the long term. It will prevent the business processes of SMEs from future failure and unnecessary future costs.

\subsection{Recommendations for Future Research}

This study is limited by the results of literature that was examined. It focuses on the importance of strategic alignment for SMEs to ensure success or failure and, at the same time, highlights the need for future research. Further research is required on accounting software implementation within SMEs to identify areas of successful implementation and examine why certain SMEs succeed or fail. Some SMEs might be successful in the alignment of strategic business drivers with software functionalities, but lack the skills to successfully implement these functionalities. Future research Copyright by author(s); $\underline{\text { CC-BY }}$ 
could provide survey data on SMEs as to whether their current accounting software is sufficient to reach business imperatives. For example, one could investigate any evidence of increases in profits achieved by SMEs by switching accounting software from generic to specific?

In this paper the lack of IT personnel with relevant professional business skills to assist with proper alignment is identified as an important issue. Li et al., (2016) argue that there is a need for IT professionals to better understand business requirements. Future research is required on the different views of IT professionals of SMEs and SME management on strategic alignment. Research can also be conducted on finding ways to assist SMEs that lack skilled IT professionals in achieving strategic alignment. Finally, future research should include empirical testing of the mapping table exercise used in this study.

\section{AUTHOR BIOGRAPHY}

William Arthur Bishop is a registered Chartered Accountant of South Africa and current lecturer in management accounting for pre-graduation and post-graduation students at the South African University of Stellenbosch. William holds a Bachelors in Accountancy Honours degree as well as a Masters degree in Computer Auditing, which were both obtained through the University of Stellenbosch. He worked as a quality assurance manager for a firm in Cape Town for approximately 5 years before pursuing a career as management accounting lecturer and researcher in the field of business management. E-mail: abishop@sun.ac.za

\section{REFERENCES}

Alvarez, H., \& Iske, P. (2015). Internal capabilities and external knowledge sourcing for product innovation in LMT SMEs. Journal of Innovation Management, 2, 55-70. Retrieved from http://feupedicoes.fe.up.pt/journals/index.php/IJMAI/article/view/56

Amoako, G. K. (2013). Accounting practices of SMEs: A case study of Kumasi Metropolis in Ghana. International Journal of Business and Management, 8(24), 73-83. Retrieved from http://www.ccsenet.org/journal/index.php/ijbm/article/view/29609

Avison, D., Jones, J., Powell, P., \& Wilson, D. (2004). Using and validating the strategic alignment model. Journal of Strategic Information Systems, 13(3), 223-246. Retrieved from http://www.sciencedirect.com/science/article/pii/S0963868704000356

Azyabi, N., Fisher, J., Tanner, K., \& Gao, S. (2014). The relationship between KM strategies and IT applications in SMEs. Proceedings of the Annual Hawaii International Conference on System Sciences, 3645-3654. Retrieved from $\mathrm{http}$ ://ieeexplore.ieee.org/stamp/stamp.jsp?tp=\&arnumber $=6759055$

Bērziša, S., Bravos, G., Gonzalez, T. C., Czubayko, U., España, S., Grabis, J., ... Zdravkovic, J. (2015). Capability Driven Development: An Approach to Designing Digital Enterprises. Business \& Information Systems Engineering, 57(1), 15-25. http://doi.org/10.1007/s12599-014-0362-0

Blili, S., \& Raymond, L. (1993). Information technology: Threats and opportunities for small and medium-sized enterprises. International Journal of Information Management, 13(6), 439-448. Retrieved from http://www.sciencedirect.com/science/article/pii/026840129390060H

Boshoff, W. (2014). Business imperatives and the IT GAP. Masters in Commerce (Computer Auditing) Unpublished lecture slides. Stellenbosch University. Unpublished lecture slides (Master's in Commerce). Stellenbosch: School of Accountancy, Stellenbosch University.

Broida, M., \& Flora, D. (2015). The status of computerized accounting software in small American businesses. Journal of Small Business Strategy, 1(1), 44-59. Retrieved from http://libjournals.mtsu.edu/index.php/jsbs/article/view/219/202

Cragg, P., King, M., \& Hussin, H. (2002). IT alignment and firm performance in small manufacturing firms. The Journal of Strategic Information Systems, 11(2), 109-132. Retrieved from http://www.sciencedirect.com/science/article/pii/S0963868702000070

Davenport, T. H. (1998). Putting the enterprise into the enterprise system. Harvard Business Review, 76(4), 121-131. Retrieved from http://cas.uah.edu/guptaj/m680/davenport1.pdf

Dwivedi, Y. K., Wastell, D., Laumer, S., Henriksen, H. Z., Myers, M. D., Bunker, D., ... Srivastava, S. C. (2015). Research on information systems failures and successes: Status update and future directions. Information Systems Frontiers, 17(1), 143-157. Retrieved from http://download.springer.com.ez.sun.ac.za/static/pdf/531/art:10.1007/s10796-014-9500y.pdf?originUrl=http://link.springer.com/article/10.1007/s10796-014-9500y\&token $2=\mathrm{exp}=1435236137 \sim \mathrm{acl}=/$ static/pdf/531/art\%3A10.1007\%2Fs10796-014-9500-y.pdf?originU

Goosen, R. (2012). The development of an integrated framework in order to implement information technology governance principles at a strategic and operational level for medium-to-large sized South African businesses. Unpublished master's 
thesis. Stellenbosch: Stellenbosch University.

Goosen, R., \& Rudman, R. (2013). An integrated framework to implement IT governance principles at a strategic and operational level for medium- to large-sized South African businesses. International Business \& Economics Research Journal, 12(7), 835-854. Retrieved from http://cluteinstitute.com/ojs/index.php/IBER/article/view/7972/8026

Griffith, T., Zammuto, R., \& Aiman-Smith, L. (1999). Why new technologies fail. Industrial Management, $29-34$.

Hedtke, J. (2007). Small biz software grows up. Accounting Technology, 23(6), 33-37. Retrieved from http://web.b.ebscohost.com.ez.sun.ac.za/ehost/pdfviewer/pdfviewer?sid=915303d6-202f-469f-be8f2fee67f2ccaf@sessionmgr111\&vid=1\&hid=128

Hislop, D. (2008). Mobility and technology in the workplace. New York: Routledge.

Hussin, H., King, M., \& Cragg, P. (2002). IT alignment in small firms. European Journal of Information Systems, 11(2), 108127. Retrieved from http://search.proquest.com.ez.sun.ac.za/docview/218781374/fulltextPDF?accountid=14049

Ismail, N. A., \& King, M. (2007). Factors influencing the alignment of accounting information systems in small and medium sized Malaysian manufacturing firms. Journal of Information Systems and Small Business, 1(1), 1-20. Retrieved from https://ojs.deakin.edu.au/index.php/jissb/article/view/1/1

Kruger, W. (2011). Addressing application software package project failure: Bridging the information technology gap by aligning business processes and package functionality. Unpublished master's thesis. Stellenbosch: Stellenbosch University.

Kruger, W. (2012). Strategic business-IT alignment of application software packages: Bridging the information technology gap. South African Computer Journal, (49), 1-11. Retrieved from http://sacj.cs.uct.ac.za/index.php/sacj/article/viewArticle/90

Kyobe, M. E. (2004). Investigating the strategic utilization of IT resources in the small and medium-sized firms of the eastern Free State province. International Small Business Journal, 22(2), 131-158. Retrieved from http://isb.sagepub.com/content/22/2/131.short

Kyobe, M., Namirembe, E., \& Shongwe, M. (2015). The alignment of information technology applications with nontechnological competencies of SMEs in Africa. The Electronic Journal of Information Systems in Developing Countries, 67(5), 1-22. Retrieved from http://www.ejisdc.org/ojs2/index.php/ejisdc/article/view/1357

Lesjak, D. (2000). Small Slovene firms and strategic information technology usage. Journal for East European Management Studies, 5(2), 152-172. Retrieved from http://www.jstor.org/stable/pdf/23280136

Levy, M., \& Powell, P. (2004). Strategies for growth in SMEs information systems. Burlington: Elsevier ButterworthHeinemann.

Levy, M., Powell, P., \& Yetton, P. (2001). SMEs: Aligning IS and the strategic context. Journal of Information Technology, 16(3), 133-143. Retrieved from http://www.tandfonline.com/doi/abs/10.1080/713772781

LiLi, W., Liu, K., Belitski, M., Ghobadian, A., O'Regan, N. (2016). e-Leadership through strategic alignment: An empirical study of small- and medium-sized enterprises in the digital age. Journal of Information Technology, 31(2), 185-206. Retrieved from http://eprints.uwe.ac.uk/28888

Malefane, S. R. (2013). Small medium, and micro enterprise and local economic-base restructuring - A South African local government perspective. Journal of Public Administration, 48(4), 671-690. Retrieved from http://reference.sabinet.co.za/sa_epublication_article/jpad_v48_n4_a12

Marcelino-Sádaba, S., Pérez-Ezcurdia, A., Echeverría Lazcano, A. M., \& Villanueva, P. (2014). Project risk management methodology for small firms. International Journal of Project Management, 32(2), 327-340. Retrieved from http://dx.doi.org/10.1016/j.ijproman.2013.05.009

Matejun, M. (2014). The role of flexibility in building the competitiveness of small and medium enterprises. Management, 18(1), 154-168. Retrieved from http://www.degruyter.com/view/j/manment.2014.18.issue-1/manment-2014-0012/manment2014-0012.xml

Muscatello, J. R., Small, M. H., \& Chen, I. J. (2003). Implementing enterprise resource planning (ERP) systems in small and midsize manufacturing firms. International Journal of Operations \& Production Management, 23(8), 850-871. Retrieved from http://www.emeraldinsight.com.ez.sun.ac.za/doi/pdfplus/10.1108/01443570310486329

Olatokun, W., \& Kebonye, M. (2010). e-Commerce technology adoption by SMEs in Botswana e-Commerce Technology Adoption by SMEs in Botswana Introduction. International Journal of Emerging Technologies and Society, 8(1), 42-56. Retrieved from http://search.proquest.com.ez.sun.ac.za/docview/612933029/fulltextPDF/F60E7B529C854D1APQ/1?accountid=14049

Olsen, K. A., \& Sætre, P. (2007). ERP for SMEs - Is proprietary software an alternative? Business Process Management Journal, 13(3), 379-389. Retrieved from http://www.emeraldinsight.com/doi/full/10.1108/14637150710752290

Olugbode, M., Elbeltagi, I., Simmons, M., \& Biss, T. (2008). The effect of information systems on firm performance and profitability using a case-study approach. The Electronic Journal Information Systems Evaluation, 11(1), 11-16. Retrieved from

http://www.researchgate.net/profile/Ibrahim_Elbeltagi/publication/234015703_the_effect_of_information_systems_on_fir $\mathrm{m} \_$performance_and_profitability_using_a_case_study_approach/links/0fcfd50 $\overline{\mathrm{e}} 480 \mathrm{c} 041 \overline{\mathrm{b}} 64000000 . \mathrm{pdf}$

Park, J. (2015). Evaluating a mobile data-collection system for production information in SMEs. Computers in Industry, 68(4), 53-64. Retrieved from http://www.sciencedirect.com/science/article/pii/S0166361514002115

Pulakanam, V., \& Suraweera, T. (2010). Implementing accounting software in small businesses in New Zealand: An exploratory 
investigation. Accountancy Business and the Public Interest, 9(64), 98-124. Retrieved from http://www.researchgate.net/profile/Venkateswarlu_Pulakanam/publication/272494374_IMPLEMENTING_ACCOUNTI NG_SOFTWARE_IN_SMALL_BUSINESSES_IN_NEW_ZEALAND_AN_EXPLORATORY_INVESTIGATION/links/ 54e-6b0400cf277664ff68f80.pdf

Sahd, L.-M., \& Rudman, R. (2013, March). Governing IT through strategic alignment. Accountancy SA, 38-39.

Seethamraju, R. (2014). Adoption of software as a service (SaaS) enterprise resource planning (ERP) systems in small and medium sized enterprises (SMEs). Information Systems Frontiers, 17(3), 475-492. Retrieved from http://link.springer.com/article/10.1007/s10796-014-9506-5

Smit, S. (2009). Defining and reducing the IT gap by means of comprehensive alignment. Unpublished master's thesis. Stellenbosch: Stellenbosch University.

Temtime, Z. T., Chinyoka, S. V, \& Shunda, J. P. W. (2003). Toward strategic use of IT in SMEs: a developing country perspective. Information Management \& Computer Security, 11(5), 230-237. Retrieved from http://search.proquest.com.ez.sun.ac.za/docview/212351361/fulltextPDF/1B4142E4B0ED4775PQ/1?accountid=14049

Umble, E. J., Haft, R. R., \& Umble, M. M. (2003). Enterprise resource planning: Implementation procedures and critical success factors. European Journal of Operational Research, 146(2), 241-257. Retrieved from http://www.sciencedirect.com/science/article/pii/S0377221702005477

Webb, B., \& Schlemmer, F. (2006). Resilience as a source of competitive advantage for small information technology companies. IFIP International Federation for Information Processing, 206, 181-197. Retrieved from http://link.springer.com/chapter/10.1007/0-387-34410-1_12

Wynn, M. (2009). Information systems strategy development and implementation in SMEs. Management Research News, 32(1), 78-90. Retrieved from http://www.emeraldinsight.com/doi/full/10.1108/01409170910922041

Yetton, P., Johnston, K., \& Craig, J. (1994, July). Computer-aided architects: A case study of IT and strategic change. Sloan Management Review, (July). Retrieved from http://sloanreview.mit.edu/article/computeraided-architects-a-case-study-ofit-and-strategic-change/ 


\section{NOTES}

